\title{
O Plano Nacional de Contingência para incidentes de poluição por óleo em águas brasileiras na mídia:
} uma análise do jornal Folha de São Paulo

\section{The National Contingency Plan for oil pollution in media: an analysis of Folha de São Paulo journal}

\section{Juliana de Oliveira Vicentini}

Pós-doutoranda na Universidade de São Paulo. Doutora e Mestra em Ciências (Ecologia Aplicada Ambiente e Sociedade) pelo Programa de Pós-graduação Interunidades em Ecologia Aplicada da USP. Universidade de São Paulo, Programa de Pós-graduação Interunidades em Ecologia Aplicada, São Paulo (SP), Brasil.

\section{Carolina de Albuquerque}

Doutora em Ciências (Ecologia Aplicada - Ambiente e Sociedade) pelo Programa de Pós-graduação Interunidades em Ecologia Aplicada da USP. Universidade de São Paulo, Programa de Pós-graduação Interunidades em Ecologia Aplicada, São Paulo (SP), Brasil.

\section{Mariana Secorun Inácio}

Mestre em Ciências Criminais pelo Programa de Pós-graduação em Ciências Criminais da PUCRS. PUC-RS, Programa de Pós-graduação em Ciências Criminais, Porto Alegre (RS), Brasil. 


\section{ALCEU}

ISSN: 2175-7402

\section{Introdução}

Apesar dos desenvolvimentos científicos e tecnológicos, o mundo ainda é extremamente dependente do petróleo. Isso pode estar relacionado a sua tamanha versatilidade. Ele é a principal fonte de energia, e, a partir dele, há a derivação de diversos produtos, com destaque para gasolina, óleo diesel, querosene, produtos asfálticos, lubrificantes industriais, borracha sintética e plástico. Em 2018, o consumo planetário foi de 99,8 milhões de barris/dia, cujos maiores consumidores são Estados Unidos, China e Índia - o Brasil ocupa a sétima posição no ranking (AGÊNCIA NACIONAL DE PETRÓLEO, 2019).

Por se tratar de uma necessidade global, o transporte de petróleo circula por todo o planeta. Em 2019, o Brasil foi acometido por um derramamento de óleo em sua costa litorânea, cuja autoria é desconhecida até o presente. $\mathrm{O}$ acontecimento ganhou repercussões nacional e internacional. Diante da quantidade de óleo nas praias e da extensão de áreas contaminadas, o evento gerou uma crise ambiental no país. A partir disso, a (in)existência de políticas públicas capazes de mitigar situações como aquela - a exemplo do Plano Nacional de Contingência (PNC) - foi trazida para o debate público, sendo a mídia uma das principais fontes de informação para a população.

A aquisição de informações socioambientais ocorre de maneira mediada (HANSEN; COX, 2015). Tal mediação se dá por meio de escolas, universidades, instituições governamentais, entre outros, mas, sobretudo, por aquilo que é propagado pelos meios de comunicação de massa (HANSEN, 2015). Estes possuem papel relevante na formação das pessoas e nos debates sobre temas ambientais, bem como influenciam os direcionamentos e resultados provenientes de tais debates (HUTCHINS; LESTER, 2006). Isto ocorre por meio de símbolos, imagens e/ou narrativas que influenciam o imaginário das pessoas sobre a natureza (BAZAGO ET AL., 2020). Os desastres ambientais são integrantes desta agenda e possuem a mídia como seu principal ator social para comunicar e mobilizar as pessoas (HOUSTON ET AL.,2015).

No Brasil, poucos grupos controlam os meios de comunicação: Globo, Record, Band, SBT, Abril, Folha, Estado e Rede TV! (PASTI, 2013). A Folha de São Paulo é um jornal de propriedade do Grupo Folha. O impresso figura-se como um daqueles com maior tiragem diária no país e é detentor do maior número de seguidores nas redes sociais - na categoria jornalismo (AGÊNCIA NACIONAL DE JORNAIS, 2018).

Diversos acontecimentos do cotidiano ganham repercussão na sociedade e são transformados em pautas midiáticas. Um desses casos, conforme mencionado, foi o derramamento de petróleo nas águas da 
costa brasileira em agosto de 2019, fato que suscitou debates sobre o PNC voltado a incidentes com óleo. O Plano Nacional de Contingência (PNC) foi tema de algumas publicações. Os impactos ambientais decorrentes do derrame de óleo no Brasil em 2019 também já foram discutidos cientificamente (SOARES ET AL., 2020). No entanto, artigos a respeito da cobertura dos meios de comunicação de massa sobre o PNC voltado aos incidentes de contaminação por óleo em águas brasileiras são praticamente inexistentes. Este artigo pretende contribuir para a diminuição dessa lacuna e suscitar debates que possam direcionar a atenção de diversos segmentos da sociedade para essa importante questão.

A pergunta disparadora é: de que maneira o Plano Nacional de Contingência foi abordado pela Folha de São Paulo? Por meio da análise de conteúdo (BARDIN, 2011), o objetivo geral é discutir criticamente as notícias publicadas pelo jornal impresso sobre o PNC voltado ao incidente por óleo em águas brasileiras, no período de 30 de agosto de 2019 a 30 de janeiro de 2020, a fim de identificar os mecanismos comunicacionais empregados.

\section{Mídia e Ambiente}

Os meios de comunicação de massa têm papel importante na obtenção de conhecimentos sobre o mundo. Eles "são possivelmente o centro, fórum através do qual nós, como audiências ou públicos, fazemos sentido do nosso ambiente, sociedade e política" (HANSEN, 2015, p. 28). A visibilidade da comunicação de massa é determinante para transformar as questões ambientais em preocupações políticas (HANNIGAN, 2006). Boa parte dos debates acontecem a partir daquilo que é pautado por ela, isto é, "as pessoas tendem a incluir ou excluir dos próprios conhecimentos o que a mídia inclui ou exclui do próprio conteúdo" (WOLF, 2006, p. 143).

Em virtude do poder simbólico dos meios de comunicação de massa (VAN DJIK, 2008), que é "um poder de fazer coisas com as palavras" (BOURDIEU, 1989, p. 167), eles têm força para mobilizar os mais diferentes setores da sociedade. A matéria-prima dos meios é a linguagem, a qual determina a maneira como a realidade social é representada e compreendida. A força dessa construção simbólica do mundo depende do grau de credibilidade do enunciador, que, no caso dos meios de comunicação de massa, são agentes hegemônicos. Os produtores de conteúdo, a exemplo dos jornalistas, podem definir aquilo que será transformado em pauta ou não: logo, aquilo que integrará ou não os debates públicos, o que acaba influenciando na (i)legitimação da informação. Portanto, analisar os conteúdos de enunciadores massivos 
no que tange ao meio ambiente - tema imprescindível para a manutenção da vida - é uma maneira de prestar um serviço à coletividade, no sentido de auxiliá-la a compreender o mundo criticamente e oferecer mecanismos para transformá-lo, rumo a uma sociedade equitativa e com mais conhecimento.

A agenda ambiental é complexa e extensa. Ela é composta por temáticas de educação ambiental, preservação, sustentabilidade, biodiversidade, saúde e bem-estar, ambientes terrestres e aquáticos, agricultura, recursos hídricos, consumo responsável, cidades ecológicas e mudança climática (WENDLING, ET AL., 2020), por exemplo. Os desastres ambientais também integram a pauta e comumente são objeto da cobertura midiática. Esta pode oscilar "entre a espetacularização e a vigilância cívica" (BUENO, 2017, p. 27), sendo que a primeira se dedica ao sensacionalismo para atrair a audiência, e a segunda discute o ocorrido de maneira educativa, no sentido engajar-se na promoção da prestação de serviço à comunidade.

Os desastres ambientais podem converter-se em grandes crises para as nações, cuja mitigação pode ocorrer por meio da mobilização de instituições públicas, privadas, atingidos, voluntários e da própria imprensa (SPENSE ET AL., 2007; HOUSTON, ET AL., 2015). A conversão desses episódios em pautas pode mobilizar ações a fim de minimizar o desastre; por essa razão, a mídia é considerada uma das principais ferramentas à disposição da sociedade para criar percepções ambientais sobre os riscos provenientes do fato em questão (MILES; MORSE, 2007).

Diversos desastres ambientais - ocorridos por causa natural ou em decorrência de negligência antrópica - têm sido transformados em pautas midiáticas e objeto de pesquisas sobre mídia e ambiente. Entre tantos, destacam-se as análises sobre a cobertura do desmatamento (LADLE ET AL., 2010) e incêndios florestais na Amazônia (SILVA ET AL., 2019), crise hídrica em São Paulo (MARTIRANI; PERES, 2016), rompimento das barragens em Mariana (FONTES; LOPES, 2017) e Brumadinho (SILVA ET AL., 2020), furacões (KEMPTON, 2019) e terremotos (LAMBERT, 2020). O vazamento de óleo na costa brasileira também foi noticiado pela imprensa e é objeto de análise do presente estudo.

\section{O derramamento de óleo na costa brasileira}

O processo de formação histórica, geográfica, social e econômica do território brasileiro iniciou-se em áreas litorâneas (IBGE, 2011). Parte da concentração demográfica brasileira localiza-se na zona costeira, que atualmente abriga $26,6 \%$ da população do país, distribuída em 280 municípios, espalhados por 17 unidades da federação (IBGE, 2018). No litoral brasileiro, desenvolvem-se diversas atividades. A 
maioria de sua população ocupa-se com turismo, pesca, produção de petróleo e gás. Ademais, a região é rota frequente de diversas embarcações, a exemplo daquelas responsáveis pelo transporte de óleo (petróleo cru).

O Brasil foi o cenário do maior vazamento de óleo de sua história em águas costeiras. Os primeiros registros do desastre datam de 30 de agosto de 2019. Este ocorrido espalhou-se por mais de três mil e seiscentos quilômetros nas regiões Nordeste (Paraíba, Bahia, Ceará, Maranhão, Paraíba, Pernambuco, Piauí, Rio Grande do Norte e Sergipe) e Sudeste (Espírito Santo e Rio de Janeiro) (SOARES, et al., 2020), totalizando 1.009 localidades atingidas, distribuídas em 130 municípios (IBAMA, 2020), o que corresponde a um quarto da costa brasileira (SOARES ET AL., 2020). Cerca de cinco mil toneladas de óleo foram retiradas das praias (NEXO, 2019).

Na tentativa de apurar o desastre socioambiental, a Marinha brasileira iniciou um processo de investigação e notificou dez países que tinham navios petrolíferos navegando próximos à costa brasileira para prestarem esclarecimentos sobre suas atividades. Diante disso, algumas hipóteses de responsabilidade foram consideradas: entre elas, aquelas relacionadas a navios de origem da Venezuela, Grécia e África; naufrágio de petroleiro; falha na transferência de petróleo entre embarcações (ship-toship); despejo criminoso. Em agosto de 2020, o desastre completou um ano, e o inquérito aberto pela Marinha não identificou o responsável.

Desastres dessa natureza geram danos de diversas ordens. No âmbito ambiental, ocorre a contaminação de corais, mangues, águas e seres vivos, e até mortandade destes últimos. Do ponto de vista econômico, a contaminação de peixes impede que eles sejam utilizados para a comercialização; a poluição das praias gera queda no mercado turístico. Socialmente, há implicações psicológicas, riscos à saúde e declínio da qualidade de vida. A contaminação pelo óleo se estende à população humana. Os banhistas frequentadores das áreas, os moradores locais e os voluntários envolvidos na limpeza e contenção do avanço do óleo nem sempre possuem equipamentos apropriados de proteção e comumente têm contato direto com a substância, o que acarreta a inalação de vapores de óleo e queimaduras na pele.

Salienta-se que os impactos mencionados não se restringiram às praias apenas, mas também aos rios que desembocam nas áreas afetadas. A foz do Rio São Francisco, localizada na divisa entre Alagoas e Sergipe, foi acometida pelas manchas de óleo. A fim de que o óleo não invadisse o rio, ações de contenção 
para evitar tal poluição foram determinadas judicialmente sob o risco de comprometer o abastecimento das cidades ao longo da costa brasileira (MINISTÉRIO PÚBLICO FEDERAL, 2019).

Diante da gravidade da situação, algumas ações foram colocadas em prática. O Projeto Tamar, em conjunto com o Instituto de Desenvolvimento Sustentável e Meio Ambiente do Rio Grande do Norte IDEMA, lançou um material educativo alertando para as práticas preventivas e para os procedimentos no caso de contato humano ou animal com as manchas de óleo. A sociedade civil, Organizações Não Governamentais - ONGs e órgãos vinculados ao governo (Agência Nacional do Petróleo e Instituto Chico Mendes de Conservação da Biodiversidade - ICMBio, por exemplo), promoveram ações no sentido de limpar as áreas atingidas e restringir o avanço do óleo no mar e nas praias. Ativistas da ONG Greenpeace organizaram um protesto e derramaram um simulacro de óleo na frente do Palácio do Planalto em Brasília e foram presos por crime ambiental. A fim de apurar o cenário, o Ministério Público Federal entrou com a Ação Civil Pública 23/2019 para compelir a União a implementar imediatamente o Plano Nacional de Contingência.

\section{O Plano Nacional de Contingência no Brasil}

O derramamento de óleo em águas brasileiras não é um fenômeno recente. O primeiro grande evento dessa natureza aconteceu em 1974, em razão do choque do petroleiro Takimyia Maru com uma rocha no canal de São Sebastião/SP, causando o vazamento de seis mil toneladas (POFFO ET AL., 2001). Em 1978, o navio Brazilian Marina também provocou um vazamento de óleo por acidente, o que desencadeou certas medidas governamentais de prevenção e controle (POFFO ET AL., 2001). Em 2000, o rompimento de um duto da Petrobrás que ligava a Refinaria Duque de Caxias ao terminal Ilha d'Água, no estado do Rio de Janeiro, gerou um vazamento de mais de um milhão de litros de óleo, fazendo com que o plano de resposta a acidentes com essa característica fosse repensado.

Em razão do risco de novos acidentes, com suporte na Lei 9.966/2000, foram instituídos três planos para lidar com o lançamento de óleo em águas brasileiras, acionáveis de forma complementar: (1) Plano de Emergência Individual - PEI (a ser aprovado no Licenciamento Ambiental do empreendimento); (2) Plano de Área (consolidação de vários PEI em determinada área geográfica, aprovado pelo órgão licenciador, além da integração entre os planos descritos para determinada área); (3) Plano Nacional de Contingência recorte temático desta análise. 
Segundo o Art.2으, Lei 9.966/2000, o Plano Nacional de Contingência (PNC) é o conjunto de procedimentos e ações que visam à integração dos diversos Planos de Emergência setoriais, bem como a definição dos recursos humanos, materiais e equipamentos complementares para a prevenção, controle e combate à poluição das águas, direcionado a situações de maiores proporções, nas quais ações individualizadas não são suficientes para lidar o problema.

Os agentes envolvidos no PNC são: (a) Autoridade Nacional (Ministério do Meio Ambiente, que coordena as atividades); (b) Comitê Executivo (que fixa as diretrizes); (c) Grupo de Acompanhamento e Avaliação (determina se o incidente é de relevância nacional, o que dá subsídio para o coordenador operacional acionar o PNC); (d) Coordenador Operacional (acompanha o acidente e aciona o Plano Nacional de Contingência); (e) Comitê de suporte (apoia os demais quando demandado) (MINISTÉRIO DE MINAS E ENERGIA, 2012).

Os comitês se organizam com participação popular, havendo uma ampliação da atuação para além da órbita do poder público. Além disso, todos os agentes envolvidos estão em uma estrutura concatenada que depende inicialmente do acionamento do Plano pela Autoridade Nacional.

As despesas são por dotação específica do orçamento e se dividem em implementação, manutenção e monitoramento, e ações de resposta ao incidente, sendo que estas últimas devem ser repassadas ao poluidor (MINISTÉRIO DE MINAS E ENERGIA, 2012).

As estratégias de implantação governamentais iniciais tiveram como objetivo a implantação de programas internos de capacitação e de treinamento e encaminhamento para o Conselho Nacional do Meio Ambiente - CONAMA de proposta de critérios objetivos e matriz de apoio à decisão para a utilização de métodos e técnicas de combate à poluição por óleo (MINISTÉRIO DE MINAS E ENERGIA, 2012).

Entre 2000 e 2012, o Plano foi acionado em Acidente no Paraná (2000), em razão de um vazamento de quatro milhões de litros de petróleo para o rio Bariri e Iguaçu de um duto que ligava a refinaria de Araucária. Contudo, em vazamento no Campos dos Frades (2011), de responsabilidade da Chevron, no importe de 380 mil litros de óleo lançados em dez dias em águas profundas, sem mortes e sem toque na costa brasileira ou em "áreas sensíveis", o Plano não foi acionado (MINISTÉRIO DE MINAS E ENERGIA, 2012). O acidente nos Campos dos Frades implicou a alteração dos procedimentos realizados em casos de 
não acionamento do PNC, o que foi realizado no segundo vazamento no mesmo local (MINISTÉRIO DE MINAS E ENERGIA, 2012).

A regulamentação específica de um Plano de Nacional de Contingência ocorreu com o Decreto Federal 8.127/2013, que fixou responsabilidades, estabeleceu estrutura organizacional e definiu diretrizes, procedimentos e ações, com o objetivo de permitir a atuação coordenada de órgãos da administração pública e entidades públicas e privadas para ampliar a capacidade de resposta em incidentes de poluição por óleo que possam afetar as águas sob jurisdição nacional, minimizar danos ambientais e evitar prejuízos para a saúde pública.

Constatado o risco de toque de óleo na costa brasileira, o Grupo de Acompanhamento e Avaliação deve comunicar imediatamente aos órgãos estaduais do Meio Ambiente de cada um dos estados potencialmente afetados, e ao representante do Ministério da Saúde no Comitê de Suporte. A partir disso, medidas necessárias à proteção da saúde humana são adotadas, independentemente de o incidente ser considerado como de significância nacional. A Autoridade Nacional poderá solicitar a participação de outros órgãos e entidades federais, além de órgãos e entidades estaduais e municipais, e de entidades privadas.

\section{Metodologia}

A análise compreende as notícias publicadas no período de 30 de agosto de 2019 a 30 de janeiro de 2020 pelo jornal impresso Folha de São Paulo. Esse recorte temporal contempla cinco meses de monitoramento das publicações, cuja data inicial se refere à data do derramamento de óleo na costa brasileira. As notícias publicadas naquele período foram selecionadas e investigadas por meio da análise de conteúdo (BARDIN, 2011).

A análise de conteúdo tem sido um dos principais recursos metodológicos empregados para analisar a cobertura dos meios de comunicação de massa no Brasil e no mundo sobre assuntos relacionados ao ambiente (BAUM, 2012). Por meio desta ferramenta, é possível identificar os temas, sentidos, ênfases, silenciamentos, fontes de notícias, perfil das mensagens e de seu enunciador, efeitos na audiência/leitores e outros elementos que compõem (ou não) aquilo que é veiculado pelo meio de comunicação selecionado (NEUENDORF, 2017). 
O conteúdo é aquilo que já é essencialmente texto (notícias de jornais, publicidades, sites, cartas, diários de campo, artigos, teses, entre outros), ou ainda aquilo que pode ser materializado textualmente (músicas, entrevistas, palestras, comerciais etc.).

A análise de conteúdo pode ser conduzida de diversas maneiras, isto é, de acordo com o referencial teórico selecionado. No presente artigo, ela baseia-se nas diretrizes de Bardin (2011, p. 44), cujo objetivo é “obter por procedimentos sistemáticos e objetivos de descrição do conteúdo das mensagens indicadores [...] que permitam a inferência de conhecimentos relativos às condições de produção/recepção [...] destas mensagens".

Trata-se de uma ferramenta de pesquisa utilizada para investigar quaisquer conteúdos por meio de indicadores numéricos ou não, objetivando descrevê-los para além de uma leitura comum, fornecendo informações complementares sobre eles.

A análise de conteúdo desdobra-se em três etapas: (1) pré-análise; (2) exploração do material; (3) tratamento dos resultados (BARDIN, 2011) (Figura 1).

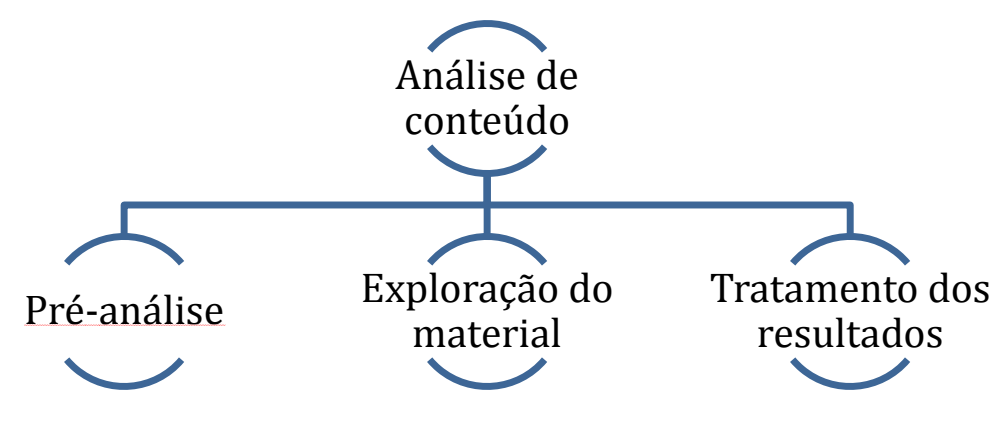

Figura 1 - Etapas da análise de conteúdo.

Fonte: as autoras a partir de Bardin (2011).

1 - Pré-análise: é o primeiro passo para colocar a análise de conteúdo em prática. Ela contempla a estruturação da investigação, seleção daquilo que será analisado, realização de uma leitura flutuante do 
corpus (primeiro contato realizado para familiarizar-se com o material), escolha dos indicadores de análise e preparação da análise. Nesta etapa, as notícias sobre o PNC e o derramamento de óleo na costa brasileira foram selecionadas a partir desses critérios: (1) recorte temporal (cinco meses de monitoramento: de 30 de agosto de 2019 a 30 de janeiro de 2020); (2) categoria de conteúdo (exclusivamente notícias - demais materiais, como artigos de opinião, seção de cartas e publicidades não foram considerados); (3) presença de determinadas palavras-chave (Plano Nacional de Contingência; plano de ação; plano de contenção) no título das notícias que se relacionam com a temática de estudos.

2 - Exploração do material: é a segunda etapa da análise de conteúdo, e trata-se da realização da análise. Ela envolve a escolha de (a) unidade de registro e de (b) contexto. A (a) unidade de registro é aquela submetida a categorização e contagem frequencial. No presente estudo, a unidade de registro selecionada é a palavra plena, ou seja, aquela "portadora de sentido" (BARDIN, 2011, p. 82), que carrega significado consigo por si só, a exemplo de adjetivos, substantivos e figuras de linguagem, e as fontes de notícias (sujeitos ou organizações/instituições). A (b) unidade de contexto objetiva identificar encadeamentos de sentido da unidade de registro: "esta pode, por exemplo, ser a frase para a palavra e o parágrafo para o tema" (BARDIN, 2011, p. 82). As unidades de registro são analisadas dentro da unidade de contexto, pois uma palavra plena isolada limita a compreensão de sua significação. Nessa etapa, a regra de contagem da unidade de registro também é definida. Neste artigo, ela é a frequência das palavras plenas, ou seja, o levantamento do número de vezes que ela aparece no corpus. Este procedimento quantitativo foi realizado por meio do software Lexico 3 - programa de análise textométrica. Por fim, nesta etapa ocorre a decomposição dos dados, isto é, a classificação das unidades de registro, que, no presente caso, ocorre por meio do critério semântico, no qual as palavras plenas que apresentam os mesmos assuntos são agrupadas em uma mesma categoria temática.

3 - Tratamento dos resultados: é a terceira e última fase da realização da análise de conteúdo. Ela envolve o manuseio dos dados para torná-los significativos (BARDIN, 2011), os quais são expressos na presente pesquisa por meio da geração de tabelas, quadros e gráficos. A partir disto, é possível interpretálos e atingir o objetivo geral proposto. 


\section{Resultados e discussão}

O recorte temporal da presente análise compreende cinco meses de monitoramento das notícias no jornal impresso Folha de São Paulo: de 30 de agosto de 2019 a 30 de janeiro de 2020. No período selecionado, o conteúdo escolhido foi a notícia. Isso significa que artigos de opinião dos colunistas do jornal supracitado, publicidades ou outros tipos de materiais não compõem a amostra. $O$ critério para a seleção do corpus foi a presença da palavra-chave "Plano Nacional de Contingência", "plano de ação", "plano de contenção", seja no título ou no corpo da notícia. Após a aplicação desse critério de seleção, identificaram-se 27 resultados. Desse montante, 20 conteúdos relacionavam-se ao tema de pesquisa aqui proposto: derramamento de óleo na costa brasileira.

De acordo com o levantamento realizado, o Plano Nacional de Contingência para Incidentes de Poluição por Óleo foi transformado em pauta pela Folha de São Paulo a partir do dia 11 de outubro daquele ano, ou seja, cinquenta dias após o desastre socioambiental. Ele seguiu ocupando as páginas do impresso até o dia 24 de dezembro de 2019. Daquela data até 30 de janeiro de 2020, o tema não foi mais abordado pelo jornal.

Após o levantamento das notícias para composição do corpus, realizou-se a leitura flutuante (BARDIN, 2011) das 20 publicações. Constatou-se que, embora haja 20 notícias que citaram o PNC - que é um plano de ação -, apenas três delas trazem a temática no título (Quadro 1): "Governo Bolsonaro extinguiu comitês do plano de ação de incidentes com óleo", publicada no dia 11/10/2019; "Procuradoria recorre ao TRF-5 e alega que união ainda não acionou plano de contenção de óleo", publicada em 28/10/2019; "Justiça determina que União integre estados do NE em plano para conter óleo", publicada em 31/10/2019 (Quadro 1). Este indicador demonstra que o PNC não foi o protagonista das 17 publicações, sendo apenas citado, em diálogo com outros temas sobre o derramamento de petróleo. A Folha de São Paulo publicou três notícias dedicadas exclusivamente a ele, apenas. Portanto, a análise de conteúdo ora em tela dedica-se às três notícias supracitadas. 
Quadro 1 - Notícias publicadas sobre o PNC-IPO na Folha de São Paulo que compõem a análise

\begin{tabular}{|l|l|l|}
\hline DATA & TíTULO DA NOTíCIA & CADERNO \\
\hline $19 / 10 / 2019$ & $\begin{array}{l}\text { Governo Bolsonaro extinguiu comitês do plano de ação de incidentes com } \\
\text { óleo }\end{array}$ & Ambiente \\
\hline $28 / 10 / 2019$ & $\begin{array}{l}\text { Procuradoria recorre ao TRF-5 e alega que união ainda não acionou plano de } \\
\text { contenção de óleo }\end{array}$ & Ambiente \\
\hline $31 / 10 / 2019$ & $\begin{array}{l}\text { Justiça determina que União integre estados do NE em plano para conter } \\
\text { óleo }\end{array}$ & Ambiente \\
\hline
\end{tabular}

Fonte: as autoras.

O jornal Folha de São Paulo é organizado por cadernos, ou seja, seções temáticas direcionadas à discussão de assuntos específicos. Entre os cadernos diários, destacam-se Poder (sobre política), Ciência (contempla as pesquisas), Mundo (a respeitos dos acontecimentos internacionais), Cotidiano (que cobre fatos do dia a dia), Esporte (jornalismo esportivo), Mercado (aborda questões econômicas) e Ilustrada (agenda e dicas culturais). Todas as notícias selecionadas foram publicadas no caderno "Ambiente", dedicado à cobertura de temas relacionados ao meio ambiente.

Após a seleção das três notícias, realizou-se a contagem frequencial da unidade de registro (palavras plenas) que mais aparecem no corpus. Para se chegar ao indicador, todas as notícias foram transcritas integralmente para arquivo em formato txt. A partir disto, elas foram lançadas no software Lexico 3, que auxiliou na codificação dos dados. Excluindo as preposições e conjunções, seguem as 20 palavras plenas com maior frequência nas notícias selecionadas (Gráfico 1). 
Gráfico 1 - Levantamento das 20 palavras mais frequentes nas notícias selecionadas

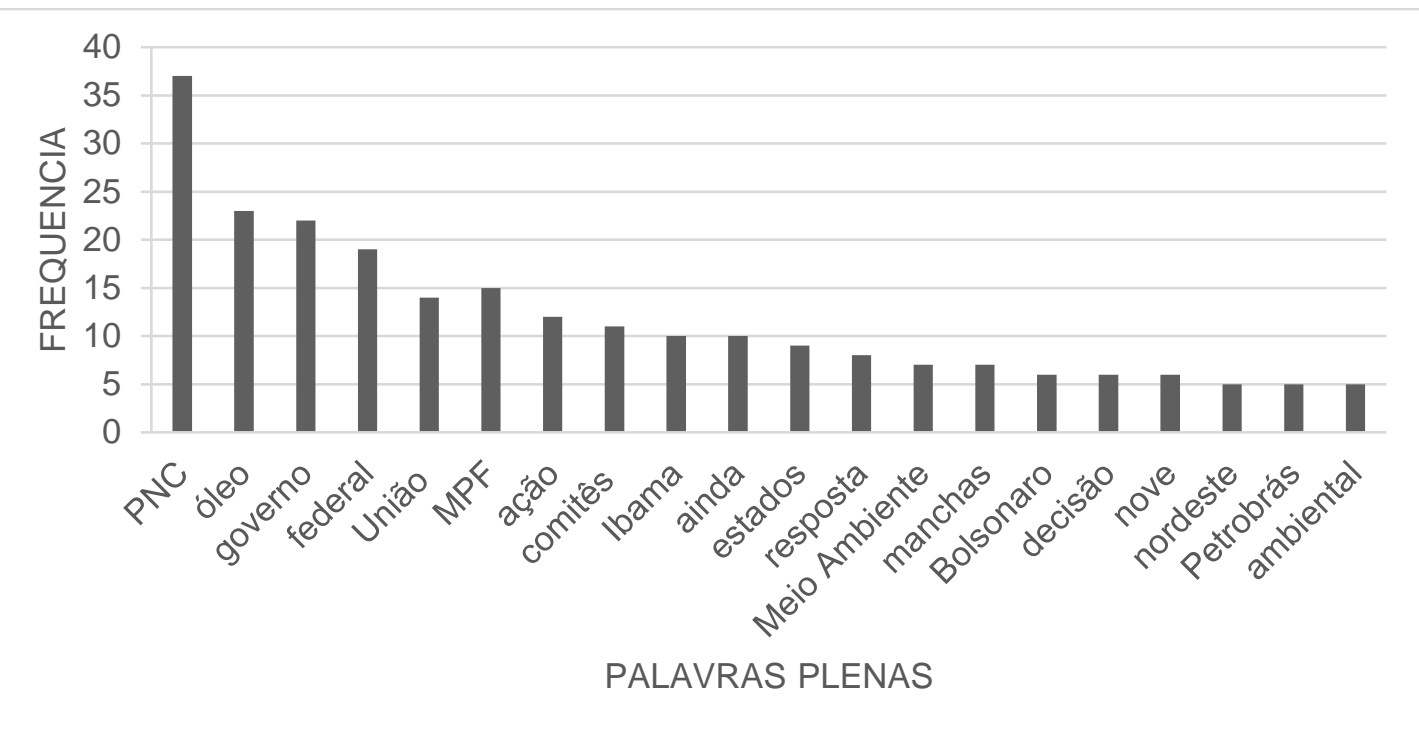

Fonte: as autoras a partir do corpus.

A palavra plena mais frequente (37 ocorrências) é "Plano Nacional de Contingência", cuja aparição ocorreu por extenso ou, ainda, por meio de sua respectiva sigla "PNC". A segunda palavra que mais apareceu foi "óleo" (23 vezes). O topo da lista formado por ambas demonstra que o PNC relacionado aos incidentes com óleo, de fato, foi o tema central das três notícias selecionadas, atingindo o recorte temático proposto.

Na sequência, aparecem "governo" (22), "federal” (19) e “União" (14). Embora haja essa variação, a partir da análise contextual, constata-se que as três se referem ao nível de autoridade máxima do país envolvido/responsável por resolver o incidente do óleo. O Ministério Público Federal - MPF (15) foi mencionado como fonte de notícia e como agente impulsionador de ações civis públicas. A palavra "ação" (12) refere-se às diligências colocadas em prática pela Procuradoria, pelo Ministério Público e pela Justiça Federal no sentido de mobilizar providências para a crise do óleo. O vocábulo "comitês" (11) aparece para fazer referência aos comitês que integravam os PNCs e foram extintos pelo governo federal. A sigla "IBAMA" (10) foi empregada como referência a um dos órgãos coordenadores das atividades de investigação e contenção do óleo, e como fonte de informação.

O advérbio temporal "ainda" (10) foi utilizado para destacar a morosidade do governo na solução da crise do derramamento de óleo. "Estados" (9) foi mencionado como referência aos nove recortes geográficos nordestinos atingidos pelo óleo. A palavra "resposta" (8) apareceu nas abordagens que 
cobravam alguma ação do Estado para o ocorrido. "Meio Ambiente" (7) foi citado nos momentos de referência ao Ministério do Meio Ambiente ou, ainda, a seu ministro - órgão envolvido diretamente ao evento. "Manchas" (7) foi a palavra utilizada para mencionar os vestígios deixados pelo óleo nas águas e praias. "Bolsonaro" (6) é o sobrenome do atual presidente do país e foi citado como responsável pela extinção dos comitês relacionados aos PNCs. "Decisão" (6) diz respeito aos desdobramentos impetrados por diversos órgãos no sentido de compelir ações públicas para a resolução do derramamento de óleo. A palavra "nove" (6) e Nordeste (5) foram utilizadas para quantificar o número de estados e a região brasileira atingidos pelo óleo. "Petrobrás" (5) foi a empresa mencionada como uma das colaboradoras na mitigação do derrame de óleo. A palavra "ambiental" (5) foi utilizada em referência ao derramamento ambiental, o qual foi classificado como "desastre ambiental" e como menção a instituições relacionadas ao meio ambiente.

As palavras plenas que integram as notícias analisadas foram empregadas em notícias com cunho denuncista no sentido de informar a omissão do governo perante o desastre ambiental, conforme exemplificado nos trechos abaixo:

“Em ação, Procuradoria fala em omissão do governo frente ao maior desastre ambiental no litoral brasileiro".

"Segundo a Procuradoria, a União não está adotando as medidas adequadas para responder à emergência"

“[...] demora e a desorganização do governo no combate às manchas de óleo".

“União ainda não acionou Plano de Contenção de óleo".

Nas notícias analisadas, o Estado aparece incapaz de investigar e resolver a crise do derramamento de petróleo e de informar a população sobre a gravidade da situação e de suas ações de contenção. A principal fonte midiática para a apresentação das matérias são exatamente os órgãos do Poder Executivo Federal - como será discutido a seguir. Dessa forma, a inércia estatal aparece tanto na ação do Estado como agente de resolução de situações de exceção quanto como na de agente informador da sociedade, através da sua dificuldade de interlocução com a mídia. 
Outro ponto importante presente nas notícias analisadas é a demora na tomada de decisão e formação de protocolos para a proteção da saúde da população. O derrame não foi incialmente divulgado como caso de importante risco à saúde pública pelo governo e, consequentemente, na mídia, tanto no que se refere aos banhistas, aos pescadores, moradores locais e voluntários na limpeza das praias, quanto no que tange ao consumo dos insumos advindos de áreas contaminadas. Uma vez que as pessoas não tinham informação para um agir consciente, várias publicidades em diversos meios de comunicação de massa apresentaram pessoas limpando as praias sem o aparato protetivo necessário, considerando que as manchas eram formadas por substâncias tóxicas.

As notícias que constituem o corpus também pontuaram tal inércia governamental, fato que levou o Ministério Público Federal a ajuizar Inquérito Civil e Ação Civil Pública, afirmando que, na ocasião, já se passaram "mais de 40 (quarenta) dias de significativos danos ambientais, sem identificação da fonte de origem, sem a mínima ideia da extensão do vazamento". O Inquérito Civil pretendia apurar as várias denúncias relativas ao derramamento de óleo, sendo oficiados o IBAMA e o órgão estadual de proteção ambiental de Sergipe para prestar informações.

Em seguida, o Ministério do Meio Ambiente - MMA foi notificado para adoção de medidas urgentes para limpeza das praias e contenção dos danos ambientais. Não houve qualquer prestação de informações, e o MMA solicitou dilação de prazo. Reuniões foram realizadas com o IBAMA e a Petrobrás, que não se propuseram a atuar ou a disponibilizar os Planos Estratégicos de Proteção de Áreas Vulneráveis (PPAVs), o que implicou na Ação Civil Pública ora em curso, que requereu multa diária de $\mathrm{R} \$ 1.000 .000,00$ (um milhão de reais) para que a União: adotasse todas as medidas necessárias para a contenção, o recolhimento e a adequada destinação do óleo decorrente do acidente ambiental; desse início à implementação dos Planos estratégicos de proteção de áreas vulneráveis; implementasse barreiras de proteção e monitoramento, em relação aos rios; que o IBAMA monitorasse e fiscalizasse integralmente as medidas a serem realizadas; ampliasse a proteção da fauna e o monitoramento contínuo da plataforma continental marítima sob risco; disponibilizasse recursos financeiros; acionasse o PNC.

Diante do preocupante cenário das repercussões nacionais e internacionais e das pressões da sociedade civil e da justiça, 41 dias após o desastre, o Ministro do Meio Ambiente acionou o PNC. 
Cuidados importantes devem ser tomados quanto ao planejamento direcionado aos impactos da contaminação por óleo por meio de medidas de monitoramento e resposta ambiental para minimizar efeitos ecológicos, econômicos e sociais do derramamento, o que implica em delinear o grau e os efeitos da contaminação ambiental e da toxicidade ambiental do petróleo; a biodegradação e a resposta microbiana ao derramamento; e o acompanhamento dos impactos tanto nos recursos marinhos e biota costeira como nas comunidades tradicionais locais, com foco na restauração. Para tanto, é necessário cooperar nos níveis nacional e internacional, com o intuito de salvaguardar os ecossistemas ${ }^{8}$.

O Estado divulgou poucos dados, o que automaticamente acabou controlando as informações repassadas aos meios de comunicação brasileiros, fato materializado na pouca quantidade de notícias publicadas pela Folha, conforme contabilizado. Isso pode resultar em desinformação, constituindo-se como um dos principais ingredientes para formar um cenário caótico no manejo da política pública ambiental.

No corpus analisado, foram identificadas as fontes de notícias utilizadas pela Folha de São Paulo para abordar o tema em questão. As fontes de notícias "são pessoas, organizações, grupos sociais ou referências; envolvidas direta ou indiretamente a fatos e eventos de quem os jornalistas obtêm informações de modo explícito ou confidencial para transmitir ao público, por meio de uma mídia" (SCHMITZ, 2011, p. 9).

Foram identificadas 16 fontes de notícias (Tabela 1), as quais podem ser enquadradas em duas categorias, a saber: (1) oficial e (2) especialista.

Tabela 1 - Fontes de notícias mencionadas pela Folha de São Paulo

\begin{tabular}{l|l}
\hline FONTES DE NOTÍCIAS & OCORRÊNCIA \\
\hline MPF & 14 \\
\hline IBAMA & 6 \\
\hline TRF & 4 \\
\hline procuradoria & 4 \\
\hline presidente & 4 \\
\hline MMA & 4 \\
\hline juíz(a) federal & 3 \\
\hline
\end{tabular}




\begin{tabular}{l|l}
\hline FONTES DE NOTÍCIAS & OCORRÊNCIA \\
\hline governo federal & 3 \\
\hline Folha & 3 \\
\hline especialista & 3 \\
\hline ONGs & 1 \\
\hline WWF & 1 \\
\hline ambientalista & 1 \\
\hline governador & 1 \\
\hline Petrobrás & 1 \\
\hline Marinha & 1 \\
\hline Fonte: as autoras com baseno corpus.
\end{tabular}

Fonte: as autoras com base no corpus.

(1) Oficial: são aquelas fontes que possuem "função ou cargo público que se pronuncia por órgãos mantidos pelo Estado e preservam os poderes constituídos (executivo, legislativo e judiciário), bem como organizações agregadas (juntas comerciais, cartórios, companhias públicas etc.) (SCHMITZ, 2011, p. 25)”. O jornal impresso teve o Ministério Público Federal - MPF (14), IBAMA (6), Tribunal Regional Federal (4), Procuradoria Geral (4), presidente (4), Ministério do Meio Ambiente - MMA (4), juiz(a) federal (3), governo federal (3), governador (1), Petrobrás (1) e Marinha (1) como fontes de notícias oficiais. Todas elas se vinculam a pessoas relacionadas ao governo ou a órgãos de responsabilidade dele. Essa categoria totalizou 45 menções.

(2) Especialistas: são aqueles que "fornecem visões dissidentes com grande autoridade" (HERMAN; CHOMSKY, 2003, p. 82), ou seja, que possuem credibilidade em virtude de seu cargo ou profissão. No presente estudo, eles são: "Folha" (três ocorrências) do segmento jornalístico, que utiliza de si como a própria fonte de notícia e para se autopromover; "especialista" (três menções) utilizado de maneira genérica para se referir a conhecedores das áreas ambiental e de petróleo; "ONGs" (uma aparição), "WWF" (uma citação) e "ambientalista" (uma vez), que se enquadram na categoria de organizações não governamentais e seu representante, cuja pauta é ambiental. Ao todo, a categoria especialista foi mencionada 9 vezes

Embora a mídia tenha uma preferência pelas fontes oficiais - dada sua credibilidade (HERMAN; CHOMSKY, 2003) -, no presente caso, a prevalência dessas fontes indica algo preocupante para a 


\section{ALCEU}

ISSN: $2175-7402$

democracia brasileira: o governo como detentor e controlador de informações sobre o derrame de óleo. Há registros nas notícias analisadas de que órgãos governamentais estavam proibidos de se pronunciar:

"o Ibama está desautorizado de dar entrevista e repassar informações à imprensa".

“possível perceber que diversas providências estão sendo adotadas isoladamente sem a necessária coordenação e compartilhamento de informações".

A dificuldade de acesso à informação atinge o entendimento esclarecido necessário para o exercício da democracia em larga escala (DAHL, 2001) e para a formação da opinião política. Isso implica no fato de que as condições que permitem uma opinião relativamente autônoma dependem da existência de um sistema de educação (não de doutrinação) e de uma estrutura global de centros de influência e informações globais e diversos (SARTORI, 1994), o que neste caso não parece haver, uma vez que temos a carência de notícias específicas (três), somada ao controle de dados realizado pelas fontes de informação oficiais.

Ao se criar desinformação geral e sistemática, apresenta-se o problema da qualidade da informação, o que deveria ser corrigido por um sistema competitivo de multiplicidade de informantes, mas que, no caso em tela, estava centralizado no governo. Contudo, maximizar não significa necessariamente otimizar, mas todo o edifício da democracia repousa, em última instância, em relativa equidade, imparcialidade ou correção das informações transmitidas ao público, através da ética do respeito pela verdade (SARTORI, 1994).

\section{Considerações finais}

Em virtude da sua importância comercial, o transporte de petróleo é uma realidade mundial. A costa brasileira é uma das rotas do produto e foi acometida por um derramamento de óleo de autoria desconhecida. O desastre ambiental foi noticiado nas mídias nacional e internacional. Tal repercussão se deveu à extensão do acidente e ao fato de o Plano Nacional de Contingência (PNC) não ter sido acionado imediatamente, o que implicou Ação Civil Pública impetrada pelo Ministério Público Federal. A população se informou sobre o acidente e sobre as ações governamentais de maneira mediada pelos meios de comunicação de massa. A cobertura influenciou os debates e o imaginário das pessoas sobre natureza e preservação, bem como mobilizou ações sociais, transformando esta questão ambiental em preocupação política. 
A análise dos conteúdos de enunciadores massivos, que têm o poder de criar novos significados da realidade ou gerar a manutenção de antigos, é indispensável para a sua compreensão crítica, pois ela busca denunciar a espetacularização e valorizar a vigilância cívica. O presente artigo objetivou discutir criticamente o conteúdo de um jornal impresso sobre o PNC voltado ao incidente por vazamento de óleo no Brasil, ocorrido em 2019.

A análise de conteúdo das notícias da Folha de São Paulo, dentro do recorte temporal fixado, permite concluir que a temática foi transformada em pauta, havendo posterior silenciamento sobre o tema. O debate sobre o PNC, política pública apta a dar resposta ao desastre ambiental, não foi acionada imediatamente, portanto não foi pauta das publicações do jornal durante todo o período de ocorrência do vazamento. Nas oportunidades em que o PNC foi citado no título das notícias, ele foi lexicalmente o protagonista da notícia, sendo seguido por palavras que denotam a autoridade estatal, descrevendo a sua responsabilidade em relação ao PNC e a sua inação. O Ministério Público, de forma específica, foi considerado a principal fonte de notícia e agente impulsionador de ações civis públicas, apesar de se tratar também de órgão estatal.

Os assuntos que compuseram o corpus indicam, sucessivamente, as atividades de investigação, contenção do óleo e a morosidade do governo na solução da crise em questão. Isso confere certo cunho denuncista das notícias, no sentido de informar a omissão do governo perante o desastre ambiental. 0 Estado, nas notícias, mesmo como fonte oficial da informação e principal fonte midiática, queda-se inerte ou lacônico como agente informador da sociedade, controlando as informações disponibilizadas aos meios de comunicação. Como exemplo deste comportamento, ele proibiu o pronunciamento de órgãos governamentais como IBAMA e não se responsabilizou imediatamente com a tomada de decisão e a formação de protocolos para a proteção da saúde da população, sendo o PNC acionado 41 dias após o desastre.

Se a mídia aloca temporalmente as notícias, o Estado aloca os conteúdos disponíveis para a mídia dentro deste espaço de interesse, sem que informações e conclusões posteriores sobre o assunto fossem disponibilizadas, gerando desinformação. Inclusive, apesar de a mídia preferir fontes oficiais, neste caso, as fontes científicas também foram consultadas, em razão da opção estatal pela limitação do acesso à informação, o que atinge o entendimento esclarecido necessário para o exercício da democracia e para a formação da opinião política. 
Conclui-se que o poder simbólico dos meios de comunicação de massa mobiliza a agenda ambiental, inclusive no que diz respeito aos desastres ecológicos, e, no caso específico da Folha de São Paulo, a cobertura analisada sobre o vazamento de óleo se aproxima da vigilância cívica, no sentido de tentar prestar um serviço à sociedade e denunciar as dificuldades criadas pela fonte oficial para o acesso à informação, ainda que haja poucas notícias sobre o tema. A escassez de conteúdos pode estar relacionada ao silenciamento do Estado, no sentido de pouco dialogar com a sociedade sobre o desastre do óleo ou pela pauta ter sido esquecida após um inicial interesse e envolvimento da mídia pelo debate. Assim, as notícias sobre o derrame de petróleo analisadas na mídia selecionada indicam que o Estado não quer ou é incapaz de investigar, resolver e informar sobre a crise instaurada: neste último ponto, por ser também a principal fonte midiática - fonte oficial, uma vez que detém e controla o discurso, sendo a omissão estatal a principal geradora da desinformação no jornal impresso.

Juliana de Oliveira Vicentini

ORCID: $h$ ttp://orcid.org/0000-0002-9031-6679

Universidade de São Paulo, Programa de Pós-graduação Interunidades em Ecologia Aplicada, São Paulo (SP), Brasil. Doutora em Ciências (Ecologia Aplicada - Ambiente e Sociedade) pela USP E-mail: ju_vicentini@yahoo.com.br

Carolina de Albuquerque ORCID: https://orcid.org/0000-0001-8383-4972 Universidade de São Paulo, Programa de Pós-graduação Interunidades em Ecologia Aplicada, São Paulo (SP), Brasil. Doutora em Ciências (Ecologia Aplicada - Ambiente e Sociedade) pela USP E-mail: carolinadealbuquerque@yahoo.com.br

Mariana Secorun Inácio

ORCID: https://orcid.org/0000-0001-8383-4972 PUC-RS, Programa de Pós-graduação em Ciências Criminais, Porto Alegre (RS), Brasil. Mestre em Ciências Criminais pela PUCRS E-mail: mariana.inacio@mackenzie.br

Recebido em: 2 de junho de 2020.

Aprovado em: 22 de agosto de 2020. 


\section{Referências:}

AGÊNCIA NACIONAL DE JORNAIS. Mídia Nacional 2018. Disponível em: https://www.anj.org.br/site/menagenda/97-midia-nacional/5251-tiragem-impressa-dos-maiores-jornaisperde-520-mil-exemplares-em-3-anos.html. Acesso em: jan. 2020.

AGÊNCIA NACIONAL DO PETRÓLEO. Anuário Estatístico 2019. Disponível em: http://www.anp.gov.br/arquivos/central-conteudos/anuario-estatistico/2019/anuario-2019-texto-secao1.pdf. Acesso em: jan. 2020.

BARDIN, Laurence. Análise de Conteúdo. São Paulo: Edições 70, 2011.

BAUM, Lauren. It's Not Easy Being Green ... Or Is It? A Content Analysis of Environmental Claims in Magazine Advertisements from the United States and the United Kingdom. Environmental Communication, v. 6, n. 4, p. 423-440. 2012.

BAZAGO, Francisca García; GUARDIA, Maria Luisa García; GARCIA, Javier Sendra García. Environmental discourse in natural disaster scenarios, Economic Research-Ekonomska, v. 33, n. 1, p. 3093-3107, 2020.

BOURDIEU, Pierre. O poder simbólico. Rio de Janeiro: Bertrand Brasil, 1989.

BUENO, Wilson Costa. A cobertura jornalística de catástrofes ambientais: entre a vigilância e a espetacularização da notícia. Ciência \& Sociedade, v. 39, n. 1, p. 21-41, 2017.

DAHL, Robert. Sobre a democracia. Brasília: UNB, 2001.

FONTES, Roberta Neves; LOPES, Ivonete da Silva. As representações da mídia sobre o rompimento da barragem do Fundão em Mariana, Minas Gerais. Revista Espacios, v. 38, n. 34, p. 32-46, 2017.

HANNIGAN, John. Environmental Sociology. New York: Routledge, 2006.

HANSEN, Anders; COX, Robert. The Routledge Handbook of Environment and Communication. New York: Routledge, 2015.

HANSEN, Anders. Communication, media and the social construction of the environment. In: The Routledge Handbook of Environment and Communication. New York: Routledge, 2015.p. 26-38.

HERMAN Edward, CHOMSKY, Noan. A manipulação do público: política e poder econômico no uso da mídia. São Paulo: Futura, 2003.

HOUSTON, Brian; HAWTHORNE, Joshua; PERREAULT, Mildred; PARK, E. H., GOLDSTEIN, Marlon; HALLIWELL, Michael; GRIFFITH, Stanford. Social media and disasters: A functional framework for social media use in disaster planning, response, and research. Disasters, 39, n. 1, p. 1-22, 2015. 
HUTCHINS, Brett; LESTER, Libby. Environmental protest and tap-dancing with the media in the information age. Media, Culture and Society, v. 28, n. 3, p. 433-451. 2006.

IBAMA - Instituto Brasileiro de Meio Ambiente e Recursos Naturais Renováveis. Vistoria em áreas com localidades oleadas no litoral brasileiro 2020.Disponível em: https://www.ibama.gov.br/phocadownload/emergenciasambientais/2020/manchasdeoleo/2020-0319 LOCALIDADES AFETADAS.pdf. Acesso em: 02 set. 2020.

IBGE - INSTITUTO BRASILEIRO DE GEOGRAFIA E ESTATÍSTICA. Atlas geográfico das zonas costeiras e oceânicas do Brasil. Rio de Janeiro: IBGE, 2011.

. Municípios defrontes com o mar. Rio de Janeiro: IBGE, 2018.

KEMPTON, Stefanie Davis. Racialized Reporting: Newspaper Coverage of Hurricane Harvey vs. Hurricane Maria. Environmental Communication, v. 14, n. 3, p. 403-415, 2020.

LADLE, Richard; MALHADO, Ana Cláudia Mendes; TODD, Peter; MALHADO, Acácia. Perceptions of Amazonian deforestation in the British and Brazilian media. Acta Amazônica, v. 40, n. 2, p. 319-324, 2010.

LAMBERT, Catherine. Earthquake Country: A Qualitative Analysis of Risk Communication via Facebook. Environmental Communication, v. 14, n. 6, p. 744-757, 2020.

MARTIRANI, Laura Alves; PERES, Isabela Kojin. Crise hídrica em São Paulo: cobertura jornalística, percepção pública e o direito à informação. Ambiente e Sociedade, v. 19, n. 1, p. 1-20, 2016.

MILES, Brian.; MORSE, Stephanie. The role of news media in natural disaster risk and recovery. Ecological Economics, v.63, n. 2, p. 365-373, 2007.

MINISTÉRIO DE MINAS E ENERGIA. Plano Nacional de Contingência. Disponível em: https://www2.camara.leg.br/atividade-legislativa/comissoes/comissoes-permanentes/cmads/audienciaspublicas/audiencias-publicas/08-05-2012-definicao-e-criacao-de-novos-modelos-eficazes-deprevencao/apresentacoes/marco-antonio-almeida. Acesso em: jan. 2020.

MINISTÉRIO PÚBLICO FEDERAL. Urgente - desastre ambiental: óleo na costa do Nordeste. Disponível em:http://www.mpf.mp.br/se/sala-de-imprensa/docs/Agravo\%20de\%20Instrumento\%20\%20ACP\%200805679.16.2019\%20-\%20PNC\%20e\%20Regiao\%20Nordeste.pdf. Acesso em: jan. 2020.

NEUENDORF, Kymberly. The Content Analysis Guidebook. Los Angeles: Sage Publications, 2017.

NEXO. O que já se sabe e o que foi descartado sobre o óleo no Nordeste. Disponível em: https://www.nexojornal.com.br/expresso/2019/12/19/0-que-j\%C3\%A1-se-sabe-e-o-que-foi-descartadosobre-o-\%C3\%B3leo-no-Nordeste. Acesso em: jan. 2020. 
PASTI, André. Notícias, informação e território: as agências transnacionais de notícias e a circulação de informações no território brasileiro 2013. 237. Dissertação (Instituto de Geociências). UNICAMP, Campinas. 2013.

POFFO Iris; XAVIER, José Carlos de Moura.; SERPA, Ricardo Rodrigues. A História dos 27 anos de Vazamento de Óleo no Litoral Norte do Estado de São Paulo (1974-2000). Revista Meio Ambiente Industrial, v. 3, n. 1, p. 98-104. 2001.

SARTORI, Giovanni. A teoria da democracia revisitada. São Paulo: Ática, 1994.

SCHMITZ, Aldo Antonio. Fontes de notícias: ações e estratégicas das fontes no jornalismo. Florianópolis: Combook, 2011.

SILVA, Nathália Thais Cosmo; FRA.PALEO, Urbano; FERREIRA NETO, José Ambrósio. Conflicting Discourses on Wildfire Risk and the Role of Local Media in the Amazonian and Temperate Forests. International Journal of Disaster Risk Science, v. 10, p. 529-543, 2019.

SILVA, Matheus Batista; ARAÚJO, Carolina Lopes; SILVA, Janaína Siqueira. Mídia e meio ambiente: a representação de atores sociais em notícias sobre as tragédias de Mariana e Brumadinho. Investigação Qualitativa em Ciências Sociais, v. 4, p. 377-390, 2020.

SOARES, Marcelo de Oliveira et al. Oil spill in South Atlantic (Brazil): environmental and governmental disaster. Marine Policy, v. 115, n. 103879, p. 1-7. 2020.

SPENCE, Patric; LACHLAN, Kenetthe; GRIFFIN, Donyale. Crisis communication, race, and natural disasters. Journal of Black Studies, v. 37, n.4, p. 539-562, 2007.

VALADARES, João. Procuradoria recorre ao TRF-5 e alega que união ainda não acionou plano de contenção de óleo. Folha de São Paulo. Ambiente. Disponível em: https://www1.folha.uol.com.br/ambiente/2019/10/procuradoria-recorre-ao-trf-5-e-alega-que-uniaoainda-nao-acionou-plano-de-contencao-de-oleo.shtml. Acesso em: jan. 2020.

VAN DJIK, Teun. Discurso e poder. São Paulo: Contexto, 2008.

WATANABE, Phillippe. Governo Bolsonaro extinguiu comitês do plano de ação de incidentes com óleo. Folha de São Paulo. Ambiente. Disponível em: https://www1.folha.uol.com.br/ambiente/2019/10/governo-bolsonaro-extinguiu-comites-do-plano-deacao-de-incidentes-com-oleo.shtml. Acesso em: jan. 2020.

WATANABE, Phillippe. Justiça determina que União integre estados do NE em plano para conter óleo. Folha de São Paulo. Ambiente. Disponível em: https://www1.folha.uol.com.br/ambiente/2019/10/justicadetermina-que-uniao-integre-estados-do-ne-em-plano-para-conter-oleo.shtml. Acesso em: jan. 2020. 
WENDLING, Zachary; EMERSON, John; SHERBININ, Alex; ESTY, Daniel. 2020 Environmental Performance Index. New Haven: Yale Center for Environmental Law \& Policy, 2020.

WOLF, Mauro. Teorias das comunicações de massa. São Paulo: Martins Fontes, 2006.

\section{Resumo}

Os meios de comunicação de massa possuem papel fundamental para o entendimento das questões socioambientais. Em 2019, o Brasil passou por uma crise em virtude do derramamento de óleo no mar, fato que trouxe à tona a discussão do Plano Nacional de Contingência - PNC. O evento ganhou projeções internacionais e se tornou pauta da mídia. O objetivo é discutir criticamente o conteúdo da Folha de São Paulo sobre o PNC voltado ao incidente por óleo, publicado de 30/08/2019 a 30/01/2020. Três notícias foram publicadas a respeito do assunto. Essa pequena quantidade pode estar relacionada ao fato de que o jornal dependia das fontes oficiais para informar os seus leitores. O Estado mostrou-se incapaz de informar a sociedade como um todo sobre o tema, logo a mídia selecionada teve dificuldades de promover uma cobertura abrangente a respeito do desastre, comprometendo o desenrolar adequado da arena democrática.

Palavras-chave: Plano Nacional de Contingência. Folha de São Paulo. Análise de Conteúdo.

\section{Abstract}

Mass media have a fundamental part of understanding socio-environmental subjects. In 2019, Brazil faced a crisis due to the oil spillage in the ocean, that brought to discussion the National Contingency Plan - PNC. The event gained international projections and became part of the media agenda. The objective is to critically discuss the content of Folha de São Paulo about PNC towards the oil incident, published from 30/08/2019 until 30/01/2020. Three news articles were published on the subject at hand. This small amount may be related to the fact that the news journal depended on official sources to inform its readers. The State proved to be incapable of providing society as a whole about the subject, therefore the selected media showed difficulties in promoting broad coverage concerning the disaster, compromising the adequate development necessary for the democratic arena.

Keywords: National Contingency Plan. Folha de São Paulo. Content Analysis. 


\section{Resumen}

Los medios de comunicación juegan un papel fundamental en la comprensión de los problemas socioambientales. En 2019, Brasil atravesó una crisis debido al derrame de petróleo en el mar, un hecho que trajo a la discusión el Plano Nacional de Contigência - PNC. El evento ganó proyecciones internacionales y se convirtió en un tema destacado de los medios de comunicación. El objetivo es discutir críticamente el contenido del periodico Folha de São Paulo sobre el PNC centrado en el incidente del petróleo, publicado del 30/08/2019 al 30/01/2020. Se publicaron tres noticias sobre el tema. Esta pequeña cantidad puede estar relacionada con el hecho de que el periódico dependía de fuentes oficiales para informar a sus lectores. El Estado no pudo informar a la sociedad en su conjunto sobre el tema, por lo que los medios seleccionados tuvieron dificultades para promover una cobertura integral del desastre, comprometiendo el desarrollo adecuado de la arena democratica.

Palabras clave: Plano Nacional de Contigência. Folha de São Paulo. Análisis de contenido.

Este artigo é publicado em acesso aberto (Open Access) sob a licença Creative Commons Attribution Non-Commercial (CC-BY-NC 4.0), que permite que outros remixem, adaptem e criem a partir do seu trabalho para fins não comerciais, e embora os novos trabalhos tenham de lhe atribuir o devido crédito e não possam ser usados para fins comerciais, os usuários não têm de licenciar esses trabalhos derivados sob os mesmos termos. 